\title{
RUANG BERBUDAYA BETAWI KEMAYORAN
}

\author{
Sylvia ${ }^{1)}$, Rudy Surya ${ }^{21}$ \\ 1)Program Studi S1 Arsitektur, Fakultas Teknik, Universitas Tarumanagara, sylvia.315160094@stu.untar.ac.id \\ 2) Program Studi S1 Arsitektur, Fakultas Teknik, Universitas Tarumanagara, rudys@ft.untar.ac.id
}

Masuk: 20-01-2021, revisi: 21-02-2021, diterima untuk diterbitkan: 26-03-2021

\begin{abstract}
Abstrak
Perkembangan teknologi yang pesat di Indonesia, membuat budaya asing lebih mudah masuk dan hal ini menyebabkan budaya lokal menjadi kurang diminati oleh generasi baru. Ibu kota Jakarta merupakan pintu masuk utama masuknya kebudayaan asing, salah satu kebudayaan yang terpengaruh besar adalah kebudayaan Betawi. Tidak hanya akibat perkembangan teknologi saja, terdapat juga permasalahan akan kurang tereksplornya ruang komunitas Betawi yang telah disediakan di Jakarta. Akibatnya kebudayaan Betawi semakin tergerus dan terlupakan yang akan berakhir menjadi sejarah yang lama kelamaan akan menghilang diproses berhuni masa depan. Untuk mengatasi permasalahan ini, dibutuhkan perubahan cara berhuni penduduk. Dimulai dari mengubah pola keseharian generasi baru yang biasanya hanya dilakukan saat acara dan pada area tertentu saja, menjadi sebuah kegiatan yang dapat mengajak semua generasi agar dapat ikut menikmati dan mengembangkan kembali kebudayaan Betawi agar tidak tergerus oleh kebudayaan asing. Dengan memberikan sebuah wadah ruang komunitas Betawi untuk menarik dan mengikat ketertarikan masyarakat generasi sekarang, dapat memunculkan sistem berhuni dengan budaya hybrid baru. Oleh sebab itu, dirancanglah sebuah ruang berbudaya Betawi Kemayoran, dimana ruang baru ini akan menggunakan metode everydayness dan approaching terhadap permasalahan perkembangan zaman yang ada dengan memanfaatkan perkembangan teknologi informasi yang semakin canggih. Selain melestarikan kebudayaan betawi, ruang ini juga bisa digunakan sebagai penyedia sarana kerja, rekreasi, dan edukasi baru bagi masyarakat setempat.
\end{abstract}

Kata kunci: perkembangan teknologi; komunitas; kebudayaan Betawi

\begin{abstract}
Rapid development of technology in Indonesia has made foreign culture easier to enter and this has made local culture in Indonesia less attractive to new generations. The capital city of Jakarta is the main entrance for foreign cultures to enter, one of the most affected cultures is Betawi culture. Not only due to technological developments, there are also problems with the lack of exploration of the Betawi community space that has been provided in Jakarta. As a result, Betawi culture is increasingly eroded and forgotten with a new culture and it will end up as history, which will gradually disappear from the process of future habitation., which will gradually disappear from the process of future habitation. To fix this situation, a change in the way of living is needed. Starting from changing the daily patterns of the new generation which are usually only carried out during events and in certain areas, into an activity that can invite all generations to enjoy and re-develop Betawi culture so that it is not eroded by foreign cultures. By providing a space for the Betawi community to attract and bind the interests of human current generation, a new hybrid culture can be created. Therefore, Kemayoran Betawi cultural section was designed, this new space will use everydayness and approaching methods to the problems of the existing developments by utilizing the increasingly sophisticated developments in information technology. Apart from preserving Betawi culture, this space can also be used as a provider of new jobs, recreation and education facilities for the local community.
\end{abstract}

Keywords: technological development; community; Betawi culture 


\section{PENDAHULUAN}

\section{Latar Belakang}

Perkembangan teknologi telah terjadi di Inonesia. Hal ini mengakibatkan masuknya kebudayaan asing ke Indonesia, khsusunya DKI Jakarta yang merupakan pintu utama masuknya kebudayaan asing. Budaya asing yang masuk ini menjadi ancaman untuk kehidupan dari kebudayaan lokal. Masalahnya budaya asing lebih digemari untuk dipraktekan dalam proses berhuni oleh generasi muda zaman sekarang, dibandingkan budaya lokal yang terkesan kuno, tidak menarik, dan kurang penyebarannya.

Budaya yang dibahas disini adalah budaya asli dari DKI Jakarta, yaitu budaya Betawi. Akibat budaya asing bermunculan di Jakarta, kebudayaan Betawi terkena dampak yang paling besar. Budaya Betawi yang merupakan identitas kebudayaan Jakarta ini mulai dilupakan dan ditinggalkan oleh masyarakat generasi muda. Budaya Betawi ditinggalkan juga bukan hanya karena perkembangan teknologi saja, melainkan karena ruang berbudaya Betawi di Jakarta masih kurang ketersediaannya. Salah satu contohnya adalah tempat wisata Betawi Setu Babakan masih kurang terpusat dan kurang tereksplor dengan baik.

Manusia, budaya, dan masyarakat akan berubah setiap waktunya. Perubahan ini dapat berlangsung lambat (evolusi) maupun cepat (revolusi). Perubahan dalam masyarakat dilakukan dalam rangka menghadapi perubahan di sekelilingnya dan juga meningkatkan kualitas hidup mereka. Pada konteks sosial, perubahan sosial budaya merupakan gejala yang melekat disetiap masyarakat.Untuk menyiasati keadaan ini, maka dibutuhkan perubahan cara berhuni penduduk. Dimulai dari mau mengakui dan ikut mengikuti dengan bijak perubahan zaman yang ada. Kebudayaaan itu bersifat dinamis, oleh karena itu harus bisa mengikuti arus perkembangan zaman yang ada tetapi tetap tidak membuat keaslian dari budaya Betawi itu hilang. Karena pada dasarnya manusia dan budaya akan berubah setiap waktunya. Perubahan yang terjadi dapat berlangsung lambat maupun cepat. Perubahan yang terjadi inilah yang dilakukan masyarakat untuk menghadapi perubahan serta menaikan kualitas hidup mereka.

Dengan dirancangnya sebuah ruang berbudaya Betawi Kemayoran, dimana rumah budaya baru ini dapat mengikat atau mengimersif ketertarikan masyarakat Jakarta terutama generasi muda akan pelestarian kebudayaan Betawi tentunya dengan mengikuti konsep perkembangan zaman yang ada dengan memanfaatkan perkembangan teknologi yang ada, ruang komunitas budaya Betawi ini juga bisa digunakan sebagai penyedia sarana kerja, rekreasi, dan edukasi baru bagi masyarakat setempat, terutama generasi muda dan para seniman kebudayaan Betawi itu sendiri.

\section{Rumusan Permasalahan}

a. Upaya seperti apa yang bisa membuat ruang berbudaya Betawi Kemayoran ini dapat bertahan di masa depan dengan menghadapi permasalahan tergerus oleh pengaruh luar di era perkembangan teknologi ini?

b. Bagaimana melestarikan dan mengembangkan kebudayaan Betawi di kalangan masayarakat Jakarta untuk menghadapi tantangan perkembangan berbagai kebudayaan yang masuk kota Jakarta di masa depan?

\section{Tujuan}

Tujuan dari proyek yang dirancang adalah sebagai wadah untuk mengangkat dan mengembangkan kebudayaan Betawi dengan beradaptasi dan mengikuti perkembangan teknologi yang ada, agar bisa tetap lestari di masa depan, dalam konteks pariwisata, industri, edukasi. 


\section{KAJIAN LITERATUR}

\section{Dwelling}

Berhuni adalah proses tinggal manusia yang berasal dari adanya proses adaptasi dan eksperimen, proses adaptasi manusia terhadap keadaan lingkungan dan perilaku. Manusia selalu berhubungan dengan berhuni atau $d w e l l i n g$. Dalam salah satu bukunya, Christian NobergSchulz berpendapat bahwa dwelling dalam arsitektur memiliki tiga makna;

a. Ruang bertemu untuk bertukar produk, ide, dan perasaan dengan orang lain.

b. dwelling adalah di mana kita mencapai kesepakatan dengan orang lain dan akan dihadapkan untuk menerima nilai-nilai umum yang ada di masyarakat.

c. Ruang pribadi disaat kita telah menjadi dan memiliki dunia kecil kita sendiri.

Dalam berhuni, manusia tidak hanya berhubungan dengan ruang tetapi juga budaya, lingkungan, dan manusia lain. Disaat melakukan dwelling semua faktor ini saling berhubungan dan mempengaruhi satu sama lain.

\section{Ruang Berbudaya}

Ruang berbudaya adalah sebuah ruang komunitas yang memiliki satu pedoman kebudayaan. Menurut Martin dan Nakayama rumah dan internet dapat dikatakan sebagai bentuk dari ruang berbudaya. Rumah adalah tempat kita tumbuh, dan ada juga metaphorical seperti internet. Ruang-ruang ini terbagi menjadi beberapa lokasi seperti, neighborhood, kota, daerah, dan negara, ruang tersebut merupakan tempat dimana manusia bisa menjalin suatu hubungan. Ruang budaya paling awal yang kita temui adalah rumah. Rumah adalah pengaruh ruang terbesar dalam berbudaya atau mindset tentang orang lain dan diri kita sendiri.

\section{Seni dan Tradisi Kebudayaan Betawi}

Betawi berasal dari kata Batavia, dimana Batavia sendiri merupakan nama kuno kota Jakarta yang diberikan oleh Belanda. Kata Betawi mulanya digunakan untuk menyatakan suku asli masyarakat yang berhuni di Jakarta dan bahasa yang digunakan adalah bahasa Melayu Khreol. Suku Betawi sendiri berasal dari perkawinan berbagai macam campuran etnis dan bangsa yang didatangkan oleh Belanda ke Jakarta. Suku Betawi sendiri dinilai sebagai suku pendatang baru di Jakarta.

Kebudayaan Betawi memiliki kesenian dan kebudayaannya senidiri, kebudayaan dan kesenian yang ada adalah kesenian yang berasal dari campuran beberapa suku. Hal tersebut dapat dilihat dari beberapa kesenian dan tradisi yang digunakan oleh masyarakat Betawi, sebagai berikut:

\section{Ngarak Penganten}

Dalam tradisi ini terdapat banyak jenis kesenian yang digunakan, sebagai berikut:

a. Formasi pertama adalah sepasang ondel-ondel

b. Formasi kedua ada pesilat remaja lengkap dengan seragam dan senjata toya.

c. Formasi ketiga dilanjutkan dengan barisan santri sambil bermain rabanna dan membaca salawatan.

d. Formasi keempat merupakan pengantin pria

e. Formasi ke lima diisi dengan iringan musik tanjidor

f. Formasi ke enam melanjuti formasi ke lima dengan kelompok musik tradisional Betawi dengan instrument gendang, ketipung, kempul, gong, dan kenong.

g. Formasi ke tujuh adalah pengantin perempuan

h. Formasi terakhir diisi dengan pengiring pengantin perempuan yang biasa di sebut oleh orang Betawi sebagai 'pengejek'. 
Setiap formasi yang ada berasal dari banyak unsur budaya, seperti unsur budaya Arab, Cina, Eropa, maupun unsur tradisional Betawi sendiri. Formasi pertama, keenam, dan terakhir berasal dari unsur budaya tradisional Betawi. Formasi ketiga dan tujuh berunsur Cina. Formasi kelima berasal dari unsur Eropa. Hal ini menggambarkan bahwa seni Betawi terbagi ke beberapa cabang, seperti musik, tari, teater, dan membatik yang tercermin dalam tradisi ngarak penganten.

\section{Seni Pantun Betawi}

Cabang kesenian pantun Betawi merupakan cabang kesenian berisikan pantun yang berstruktur tidak mutlak atau resmi, pantun Betawi memiliki kebebasan dalam berbahasa, biasanya pantun ini baik sampiran maupun isinya, berisikan kalimat-kalimat yang memberi semangat dan menyegarkan. Pantun Betawi tidak banyak yang mengandung nasehat, biasanya pantun Betawi berisikan kalimat sindiran yang biasanya dijadikan hiburan. Menurut Saidi ciri yang paling menonjol dari kebudayaan Betawi adalah humornya yang spontan dan tidak membosankan.

\section{Cengkok Melayu}

Cengkok Melayu atau orkes Melayu sudah terkenal sejak abad ke-19. Cengkok sendiri merupakan lekukan suara yang mengalun tinggi rendah dengan vibrasi yang khas. Musik Melayu ini biasanya digunakan sebagai penggiring peragaan silat Betawi.

\section{Cokek}

Merupakan seni tari yang diiringi oleh musik gambang keromong. Cokek sendiri merupakan seni tari yang dipengaruhi oleh Cina ini dapat terlihat dari penggunaan alat musiknya te'yan, atau biola Cina. Tari cokek sendiri merupakan tarian cukup erotic yang diperani oleh pria dan wanita yang menari berdempetan. Cokek memiliki penggemar yang cukup banyak di daerah Jakarta Pusat dan pada daerah pesisir seperti Tangerang sampai Tambun, Bekasi.

\section{Wayang Betawi}

Wayang dalam kebudayaan Betawi dibagi menjadi 2 jenis, ada wayang wong dan wayang kulit. Wayang Betawi merupakan sarana hiburan, tanpa melihat historis tokoh yang dipakai.

\section{Masakan Betawi}

Masakan merupakan salah satu seni ataupun tradisi dan adat istiadat. Masak adalah hal yang paling pokok dalam keluarga Betawi. Menurut Ridwan Saidi pada rumah orang Betawi biasanya tersedia taman yang cukup besar yang digunakan sebagai tempat menanam tumbuhan yang dapat digunakan sebagai bahan memasak, contohnya pohon pisang yang dimana daunnya dapat digunakan sebagai pembungkus pepes.

\section{Ornamen Kebudayaan Betawi}

Ornamen Ragam Hias Betawi merupakan jenis-jenis ornamen yang digunakan dalam rumah adat maupun kebudayaan Betawi, sebagai berikut:

\section{Banji Swastika}

Merupakan ornament dari Cina yang dikenal dengan sebutan 'ban' yang memiliki arti sepuluh dan 'dzi' yang artinya beribu. Maka dari itu setiap rumah yang dihiasi oleh ornament ini diharapkan mendapatkan rezeki atau kebahagiaan yang melimpah. Selain itu makna lain dari banji/swastika ini adalah matahari, dimana matahari melambangkan keceriaan dan semangat hidup. 


\section{Tumpal atau Langkan}

Ornament ini biasanya digunakan pada bagian pagar depan rumah Betawi, sebagai pembatas pada area serambi. Ornament ini sendiri memiliki makna kekuatan alam. Ornament ini tidak hanya diterapkan pada arsitektur saja tetapi juga banyak digunakan untuk keperluan tekstil maupun anyaman.

\section{Tapak Dara}

Pada dasarnya masyarakat Betawi memang sudah dikenal dekat dengan alam. Tapak dara merupakan nama bunga yang memiliki khasiat mengobati berbagai macam penyakit kulit sampai penyakit dalam, hal ini menjadikan bunga tapak dara dikenal dekat oleh masyarakat Betawi dan sering dijadikan sebagai ragam hias.

\section{Bunga Delima}

Tidak hanya bunga tapak dara saja yang memiliki banyak khasiat, terdapat juga bunga delima yang memiliki khasiat yang banyak dan juga dikenal sangat dekat oleh masyarakat Betawi.

\section{Pucuk Rebung}

Ornament yang berasal dari pengaruh kebudayaan Melayu yang kemudian diadopsi menjadi kebudayaan Betawi. Pucuk Rebung sendiri memiliki bentuk yang menyerupai gigi balang yang biasanya ada di listplang atap rumah adat Betawi.

\section{Flora dan fauna}

Bentuk flora dan fauna banyak menghiasi rumah Betawi, terutama pada corak tiang-tiang utama dan pada dinding rumah. Macam hias flora yang digunakan pada rumah adat Betawi ada bunga mawar yang melambangkan kebersamaan, bunga melati dengan kesuciannya, bunga cempaka dengan keanggunannya, bunga kenanga dengan keharumannya, serta bunga sedap malam dengan kesemerbakannya. Untuk fauna sendiri terdapat buaya dengan kesetiaannya, burung gagak dengan unsur magisnya, burung merak dengan kemegahannya, kuda dengan kuat dan gagahnya, serta rusa dengan kelincahannya.

Selain ornament terdapat juga ikon dari kebudayaan Betawi yang diterapkan dalam konsep bangunan dan penetapan fungsi, sebagai berikut:

\section{Ondel-ondel}

Merupakan sepasang karakter kebudayaan Betawi yang masih sering ditemui. Ondel-ondel merupakan sepasang karakter yang melambangkan kekuatan yang memiliki kemampuan memelihara keamanan dan ketertiban, tegar, berani, tegas, jujur dan anti manipulasi.

\section{Ornament Gigi balang}

Merupakan ornament yang biasa diletakkan pada bagian listplang atap rumah adat Betawi. Gigi balang sendiri melambangkan gagah, kokoh dan berwibawa. Pada gigi balang terdapat banyak sekali model dan jenisnya.

\section{Kembang kelapa}

Merupakan pelambang kemakmuran, yang merupakan symbol dari kehidupan manusia yang bermanfaat sebagai mana manfaat dari pohon kelapa, dan menjadi symbol multikultur kebudayaan yang hidup dan berkembang di Jakarta.

Batik Betawi

Sebagai identitas lelaki yang rendah hati, sopan, dinamis dan berwibawa. 
Kerak telor

Sebagai sisi kehidupan manusia yang mengalami perubahan lingkungan secara alamiah. Kerak Telor sebagai perlambang pergaulan yang harmonis.

\section{Bir pletok}

Bir Pletok bermakna penopang hidup sehat lahir dan batin dan juga sebagai upaya mengapresiasi serta mengisi hidup yang tidak boleh kendor sampai pada titik matang.

\section{METODE}

Dalam proses penelitian, yang pertama kali dilakukan adalah mencari isu yang terjadi saat ini dan berpengaruh terhadap kehidupan manusia di masa depan. Dari pencarian tersebut ditemukan bahwa isu yang terjadi saat ini dan mempengaruhi kehidupan manusia di masa depan adalah masuknya pengaruh budaya asing akibat kemajuan teknologi yang mengakibatkan tergerusnya kebudayaan lokal. Setelah melakukan pencarian isu, metode selanjutnya yang dilakukan adalah melakukan riset terhadap penyebab munculnya isu tersebut dan hal apa yang dapat membantu menyelesaikannya. Dalam riset ditemukan bahwa salah satu penyebab tergerusnya kebudayaan Betawi adalah kurang tereksplornya ruang komunitas Betawi di Jakarta sehingga muncul peluang untuk mengajukan proyek ruang berbudaya Betawi.

Dari proyek yang ditentukan, selanjutnya dilakukan pencarian tapak yang memiliki latar belakang atau ciri khas kawasan tertentu dan ditemukan kawasan Utan Panjang di Kecamatan Kemayoran, Jakarta Pusat dengan latar belakang kawasan yang memiliki nilai historis kebudayaan Betawi yang tinggi. Setelah pencarian kawasan baru dilakukan proses merancang dengan metode everydayness serta menggunakan acuan berupa kebudayaan betawi yang digunakan dalam proses desain dan penentuan fungsi karena fungsi bangunan sebagai ruang berbudaya diharapkan dapat menyatu dan diterima oleh masyarakat sekitar.

\section{DISKUSI DAN HASIL}

\section{Analisis Kawasan}

Kawasan Utan Panjang merupakan Kawasan tidak terencana. Kawasan ini merupakan Kawasan padat penduduk dengan dilewati jalan lingkungan berupa gang-gang kecil dengan hunian yang bertipe deret/dempet.

Kecamatan Kemayoran merupakan salah satu daerah yang terkenal dengan kebudayaan Betawinya. Di Kemayoran dulunya pernah ditinggali oleh legenda-legenda kebudayaan Betawi, seperti ada legenda jagoan macan Kemayoran yaitu Murtado yang lalu dilanjutkan oleh $\mathrm{H}$. Ung dan ada juga legenda seni peran yaitu Benyamin Sueb yang merupakan cucu dari jagoan Betawi Kemayoran H. Ung. Kelurahan Utan Panjang memiliki jumlah penduduk sebanyak 14.854 jiwa. Kelurahan ini memiliki luas wilayah sebesar $54 \mathrm{Ha}$. Kelurahan ini memiliki tingkat kepadatan sebanyak $27.508 \mathrm{jiwa} / \mathrm{km} 2$. 


\section{Lokasi Tapak}

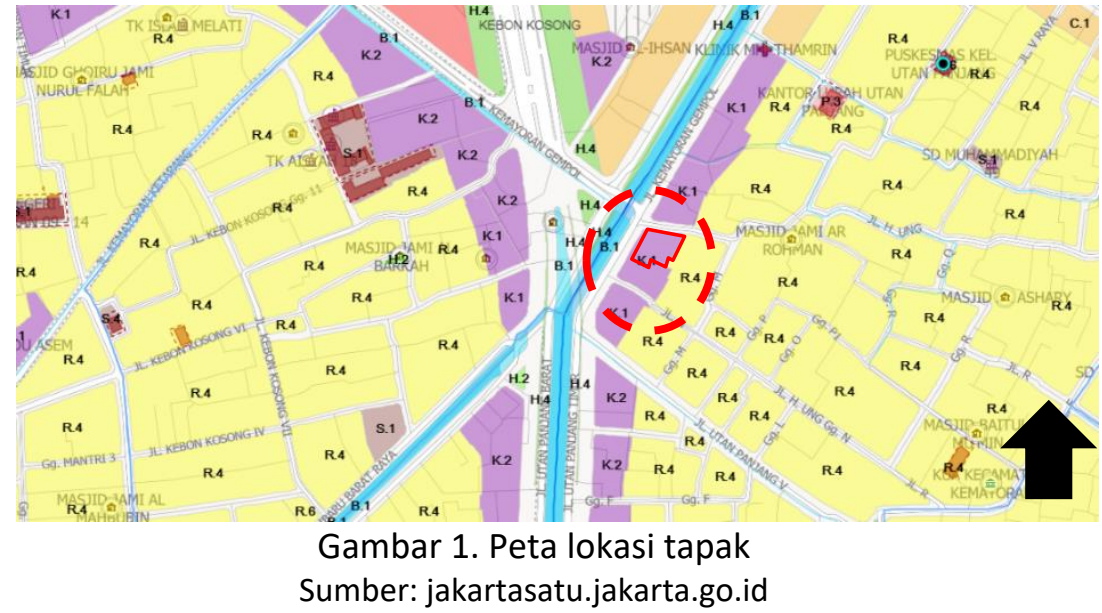

Tapak yang dipilih berada di hoek antara Jl. Utan Panjang Timur di sebelah barat dan JI. H. Ung disebelah timur. Pada Peta Perencanaan Tata Ruang DKI Jakarta di sisi utara, timur dan selatan tapak yang merupakan kawasan permukiman padat dengan ketinggian bangunan 2 lantai, selain itu terdapat juga zona pertokoan, perdagangan dan jasa dengan ketinggian bangunan 4 lantai pada sisi selatan dan utara tapak.

Proyek fasilitas edukasi dan hiburan bertemakan kebudayaan Betawi di Utan Panjang dapat digolongkan kedalam tempat bermain lingkungan, taman rekreasi, gedung seni, dan juga cafe. Maka proyek ini menjadi diizinkan pada tapak yang dipilih tersebut.

Luas Tapak adalah $2.015 \mathrm{~m} 2$, jadi berdasarkan peraturan zonasi dan tata ruang maka sesuai peraturan luas KLB, KDB, KDH, KTB adalah sebagai berikut:

- Luas KLB yang didapat : $2.015 \mathrm{~m} 2 \times 2.4=4.836 \mathrm{~m} 2$

- Luas KDB yang didapat: $2.015 \mathrm{~m} 2 \times 60 / 100=1.209 \mathrm{~m} 2$

- Luas KDH yang disyaratkan : $2.015 \mathrm{~m} 2 \times 30 / 100=604,5 \mathrm{~m} 2$

- Luas KTB yang didapat : $2.015 \mathrm{~m} 2 \times 55 / 100=1.007,5 \mathrm{~m} 2$

Pada peta zonasi, kawasan Utan Panjang didominasi oleh kawasan hunian, dengan area sekitar jalan utama yang berisi zona ungu (perkantoran, perdagangan dan jasa).

\section{Aksesibilitas}

Kelurahan Utan Panjang dapat diakses melalui dua jalan besar. Jalan arteri Jl. Benyamin Sueb yang menghubungkan kawasan Utan Panjang menuju ke arah Ancol dan Pademangan Timur, serta Jl. Utan Panjang Timur dan Barat kedua jalanan ini menghubungkan antara Jl. Benyamin Sueb dan Jl. Letjen Suprapto. Kawasan ini memiliki jalan kolektor yaitu Jl. Garuda, Jl. Kalibaru Timur. 


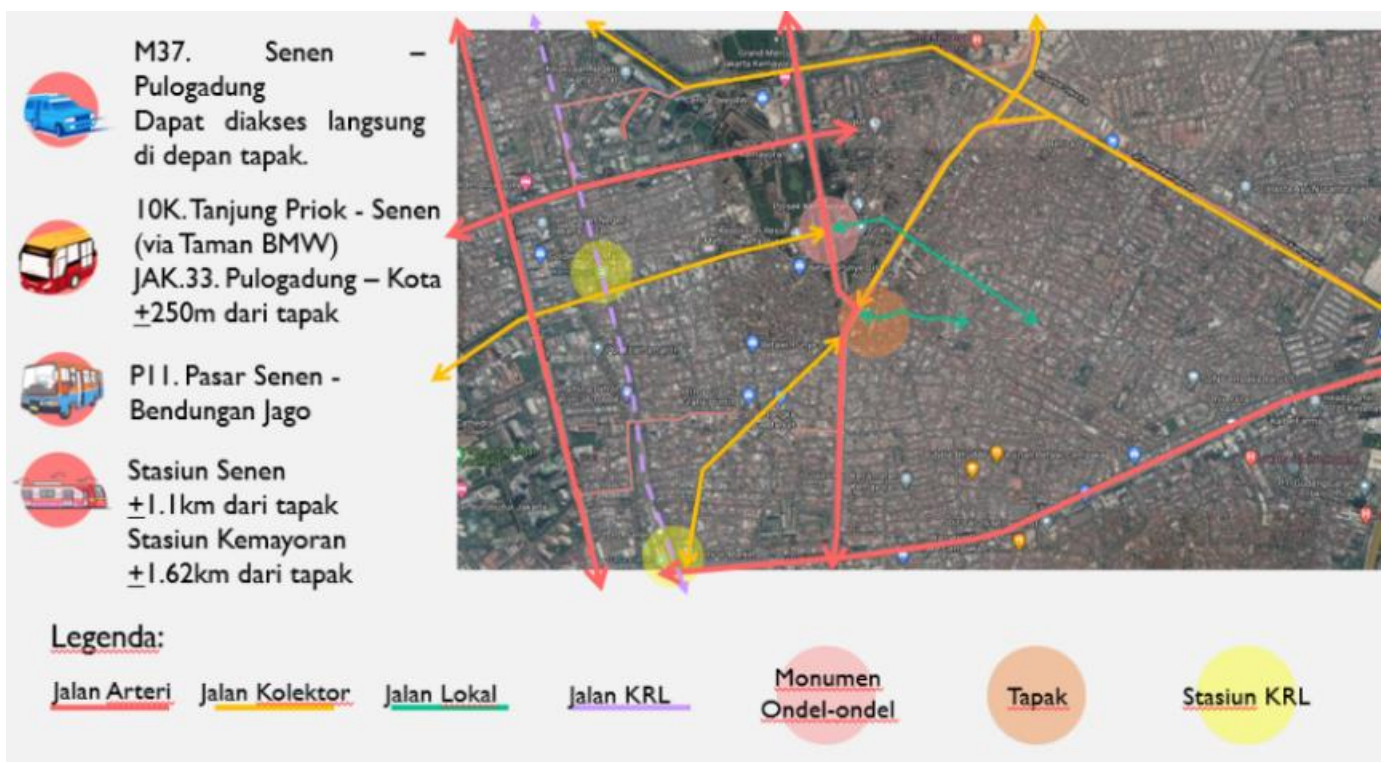

Gambar 2. Peta Sirkulasi Kawasan Kemayoran Sumber: googlemaps dimodifikasi

Transportasi yang dapat digunakan menuju tapak adalah kereta api, bus Transjakarta, Metromini, Mikrolet untuk transportasi umum, dan dapat juga menggunakan transportasi online serta kendaraan pribadi. Pada area depan tapak terdapat tempat pemberhentian bus.

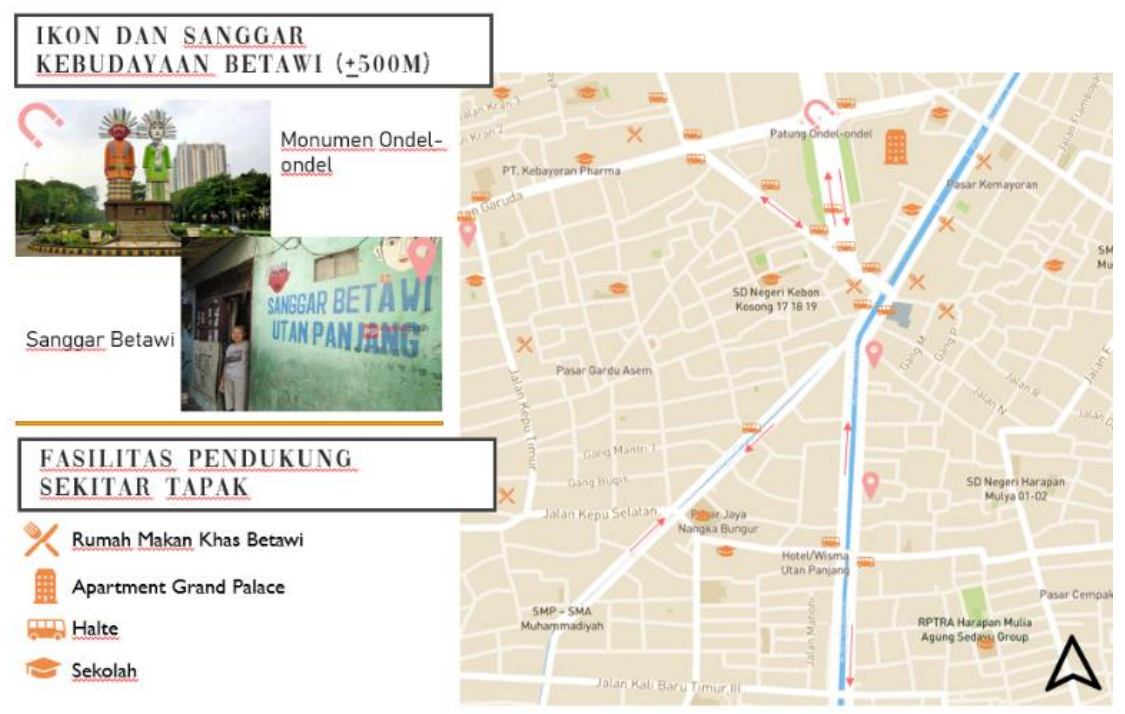

Gambar 3. Peta Sirkulasi Kawasan Kemayoran

Sumber: googlemaps dimodifikasi

Letak tapak berada dekat dengan magnet kebudayaan Betawi, seperti terdapat tugu ondelondel dan juga sanggar Betawi yang jaraknya $\pm 500 \mathrm{~m}$. Tapak yang berada di daerah Utan Panjang, tepatnya berada di J. Utan Panjang Timur dan J. H. Ung yang dimana nama Jl. H.Ung ini sendiri berasal dari salah satu nama tokoh jagoan Betawi yang menggantikan macan Kemayoran, dan lagi tapak ini dulunya merupakan daerah kekuasaan Haji Ung dengan keluarganya, dan salah satu keluarganya adalah Benyamin Sueb yang tinggalnya di sekitar lokasi tapak.

Akses pedestrian eksisting berada di sepanjang Jl. Utan Panjang Timur atau berada pada bagian barat tapak. Maka sisi sebelah barat bangunan akan menjadi akses utama masuknya pedestrian. 
Pada bagian utara tapak atau Jl. H. Ung sering digunakan pejalan kaki, hanya saja untuk keadaan eksisting masih belum mempunyai fasilitas trotoar, maka dari itu pada sisi utara tapak juga diberikan akses masuk pedestrian yang ditujukan untuk warga Utan Panjang khususnya yang tinggal di sekitaran J. H. Ung.

\section{Program Ruang}

Bangunan sebagai ruang berbudaya tidak hanya digunakan sebagai ruang berkumpulnya komunitas saja, bangunan ini juga dijadikan sebagai tempat edukasi rekreasi tentang kebudayaan Betawi berbasis observasi dan teknologi. Oleh sebab itu diusulkan 4 jenis program edukasi rekreasi yaitu:

Workshop berbudaya Betawi

Workshop disini dibedakan menjadi 2, yaitu:

a. Workshop produksi, disini merupakan acara pelatihan pembuatan sebuah produk. Jadi pada program ini sangat dibutuhkan ruang penyimpanan dan ruang cuci.

b. Workshop kesenian, disini acara pelatihan yang menghasilkan sebuah seni kebudayaan Betawi, seperti tarian, pengajian, dan musik. Sifatnya yang tidak membutuhkan barang pelengkap seperti meja dan kursi serta area cuci.

Pelatihan dengan komunitas Betawi

Program ini lebih ditujukan kepada para seniman yang ingin berkarya, apa bila workshop difungsikan sebagai pengenal untuk orang-orang baru, di pelatihan komunitas ini orang-orang dari workshop dapat langsung belajar dan ikut serta dalam pengembangan kebudayaan Betawi dengan mendaftarkan diri menjadi member dari komunitas yang ada. Pelatihan komunitas yang di sediakan adalah:

a. Komunitas silat

b. Komunitas batik Betawi

c. Komunitas pantun Betawi

d. Komunitas musik Betawi

e. Komunitas tari Betawi

f. Komunitas ondel-ondel

Perpustakaan Multimedia

Perpustakaan multimedia merupakan perpustakaan yang menyediakan buku cetak maupun $e$ book, terdapat juga audio maupun video tentang kebudayaan Betawi di perpustakaan ini. Karena terdapat penyediaan audio dan video maka diberikan juga area-area santai untuk mendengarkan audio dan ruang-ruang kecil untuk memutarkan film yang ada.

Gallery

Gallery ini merupakan pajangan berupa gambar audiovisual kebudayaan Betawi yang ditampilkan dan disusun pada area yang paling sering dilalui oleh pengunjung bangunan. 

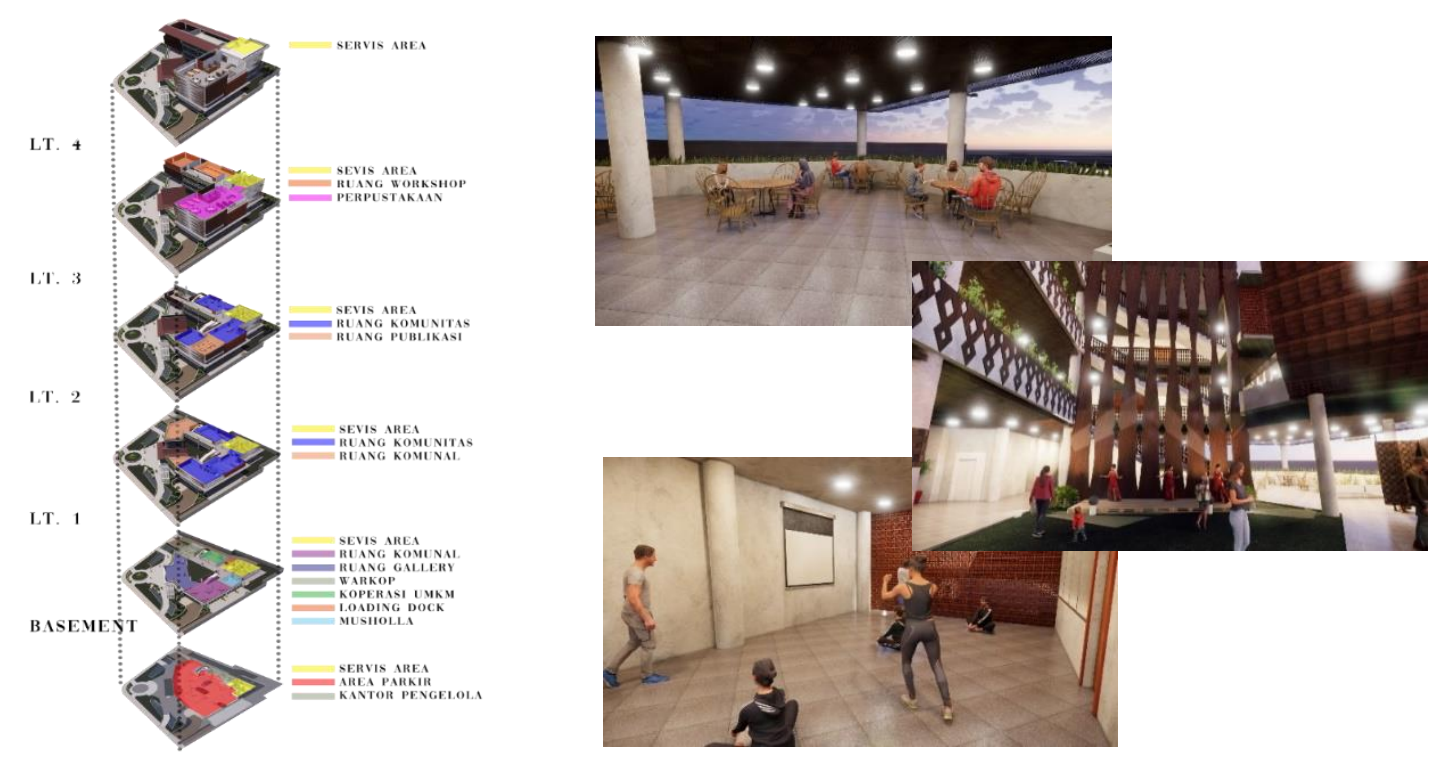

Gambar 4. Pembagian area aktivitas bangunan Sumber: Dokumentasi pribadi

\section{Gubahan Massa}
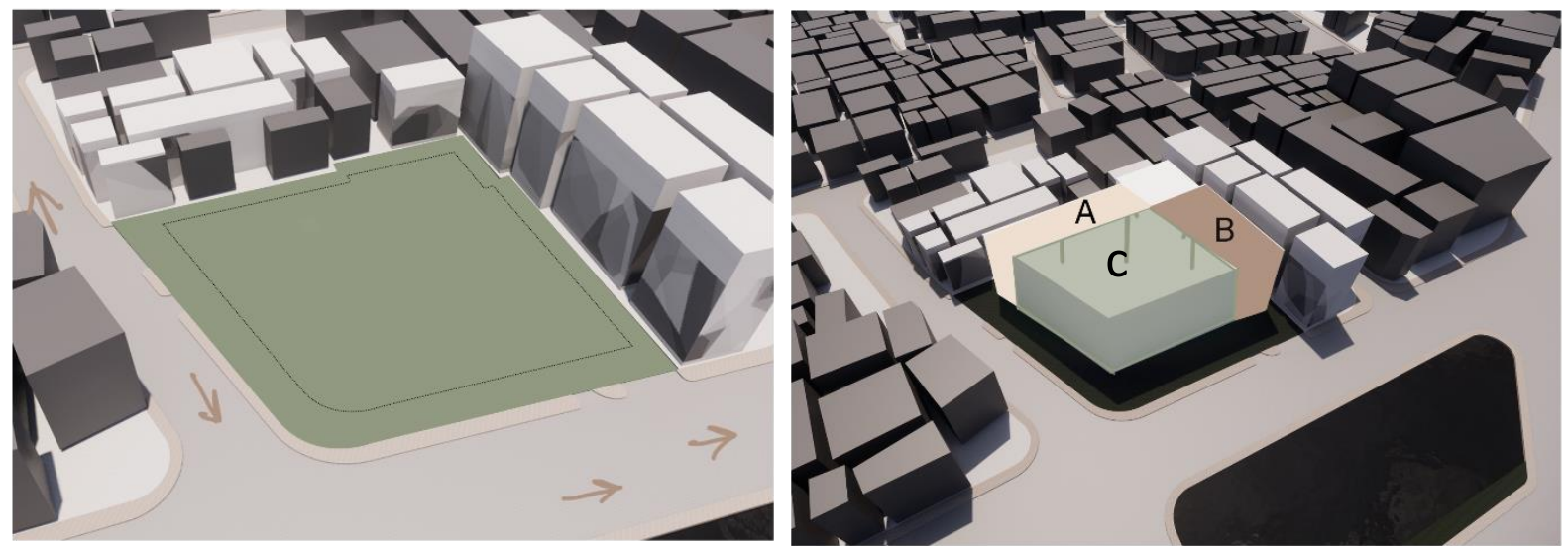

Gambar 5. Gubahan massa ke-1

Sumber: Dokumentasi pribadi

Bentukan awal gubahan massa mengikuti bentukan tapak, yaitu seperti susunan balok. Bentukan ini digunakan untuk memaksimalkan lahan yang ada. Bentukan awal ini juga digunakan untuk menjajarkan massa dengan bentukan bangunan sekitarnya. Massa kemudian dibagi menjadi 3 bagian massa. Massa A, B dan C. Massa $C$ kemudian dihilangkan untuk memaksimalkan pencahayaan pada massa $A$ dan $B$. 

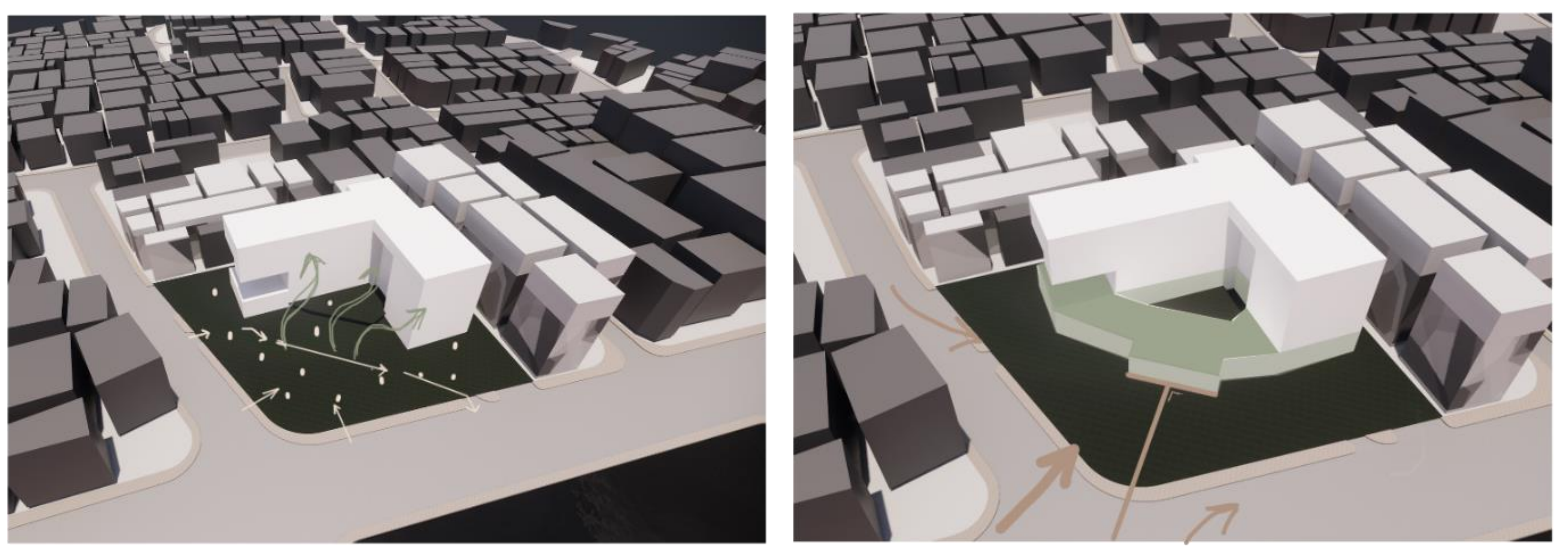

Gambar 6. Gubahan massa ke-2

Sumber: Dokumentasi pribadi

Lalu pada massa A dibuat ada area terbuka pada bagian depannya untuk dijadikan sebagai area latihan semi outdoor dan dapat dilihat dari Jl. H. Ung dan perempatan jalan, selain itu hal ini juga bertujuan untuk mengurangi kesan padat dan bulky pada bangunan. Massa c dibuang untuk memberikan ruang terbuka hijau pada area depan bangunan yang lebih luas. Kemudian pada area depan tapak ditambahkan lagi bangunan 1 lantai diagonal yang bertujuan untuk menambah luas kebutuhan ruang bangunan, serta menjadi ruang depan atau lobby bangunan. Lantai 1 bangunan dibuat pilotis. Hal ini bertujuan untuk memberikan kesan mengundang dan terbuka.
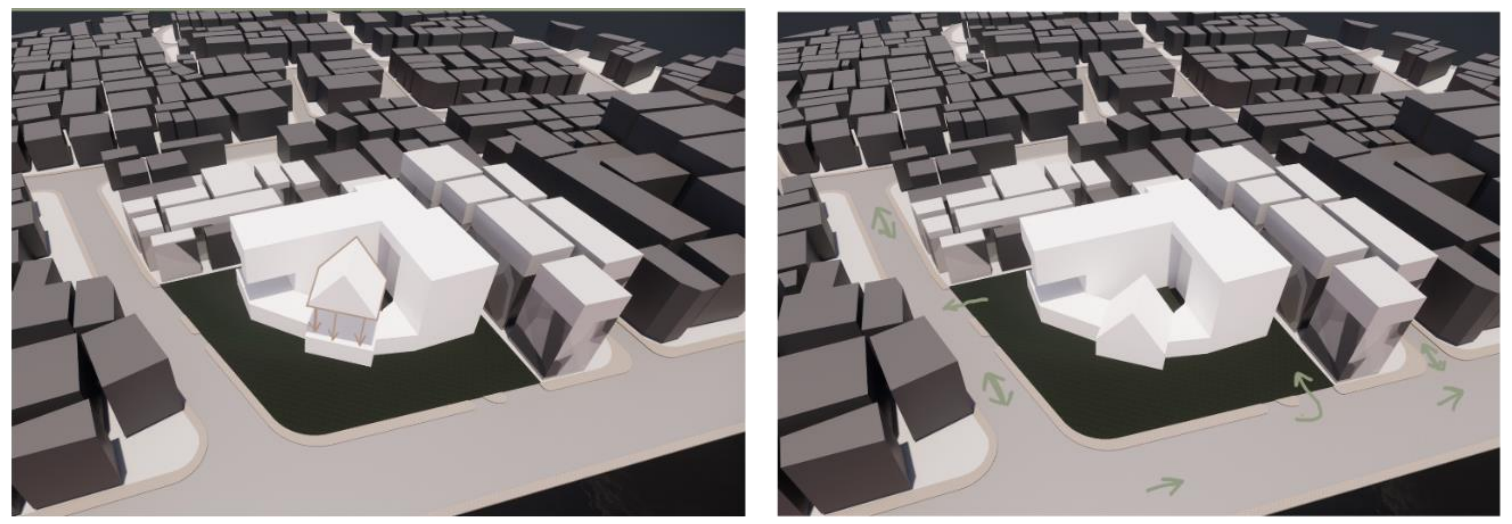

Gambar 7. Gubahan massa ke-3.

Sumber: Dokumentasi pribadi

Massa bangunan pada bagian depan lalu ditambahkan lagi massa berbentuk atap pelana yang bertujuan untuk mencerminkan atap pelana dari rumah kebaya adat Betawi. Selain itu pada massa ini dibuat void, untuk memberikan kesan ceilling yang tinggi, hal ini juga betujuan sebagai penanda akan akses utama bangunan. Area pilotis ini dapat digunakan sebagai area komunal untuk warga dalam mengadakan kegiatan.

Pada lantai 2 bangunan diberikan area terbuka. Hal ini bertujuan untuk memberikan kesan hijau pada bangunan, serta memberikan ruang komunal tambahan pada bangunan. Selain area komunal bersama area ini juga dapat digunakan sebagai area latih outdoor untuk komunitas Betawi yang ada. 


\section{Konsep Bangunan}

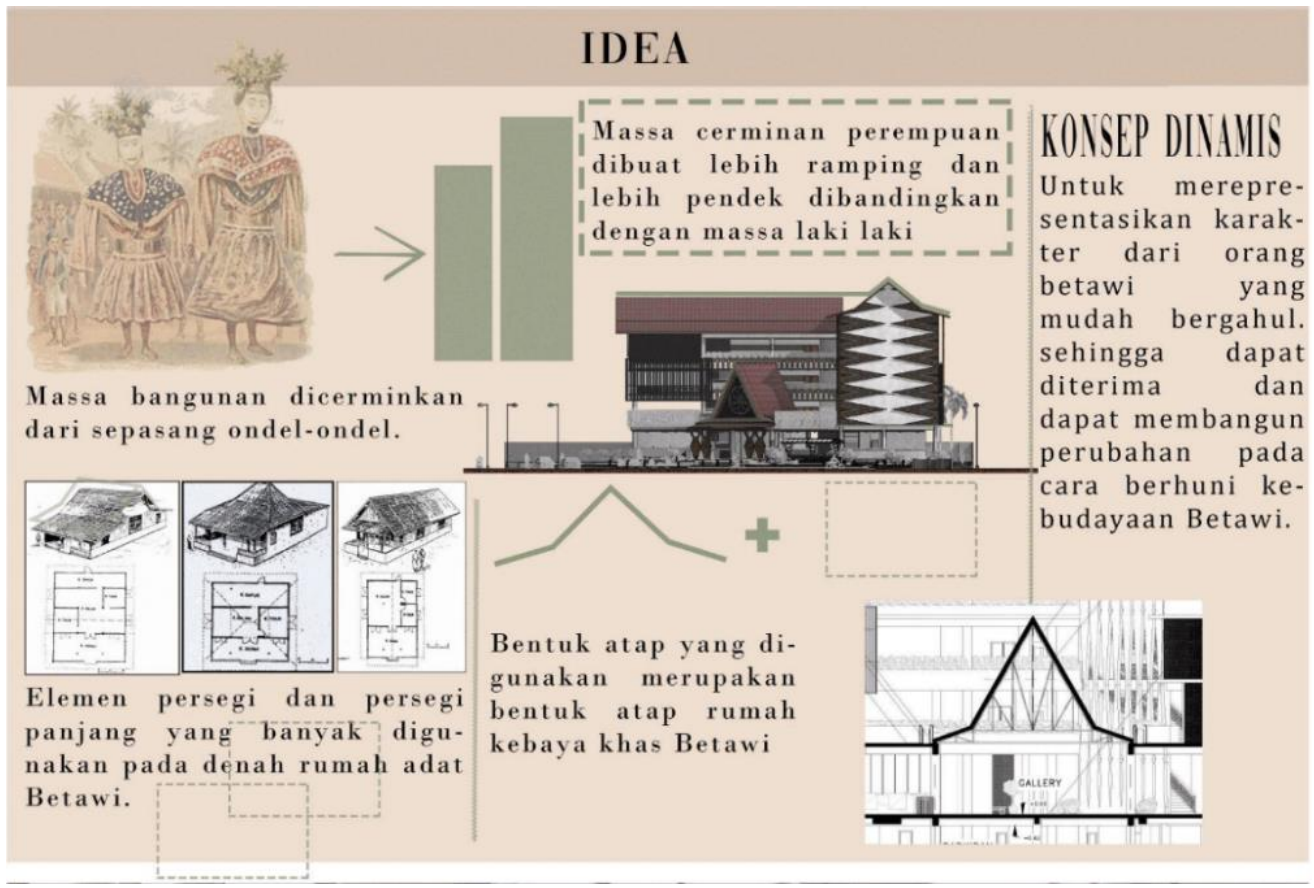

Gambar 8. konsep bangunan

Sumber: Dokumentasi Pribadi

Konsep bangunan ini didasarkan dari kebudayaan Betawi, yaitu ikon ondel-ondel yang berpasangan dan terdapat laki laki dan perempuan yang memiliki perbedaan ukuran. Serta dari bentukan rumah adat Betawi yang umumnya menggunakan unsur persegi maupun persegi panjang dengan atap pelananya. Hal ini bertujuan menambah kesan tropis pada bangunan serta menambah citra Betawi.

\section{Konsep Tampilan Bangunan}
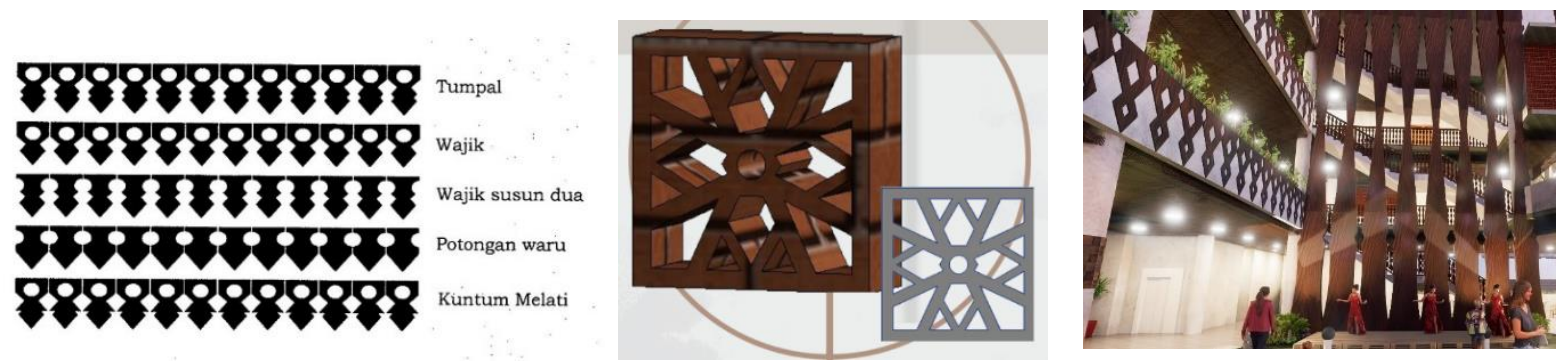

Gambar 9. Modifikasi gigi balang Sumber: Dokumentasi Pribadi

Tampilan bangunan menggunakan ornamen betawi gigi balang, melati, langkan dan atap rumah kebaya. Ornamen gigi balang diolah untuk second skin bangunan dan juga bahan pembentukan motif bata roaster. Langkan digunakan untuk railing. Sedangkan untuk bunga melati diletakan pada sopi sopi bangunan. Hal ini bertujuan untuk mencerminkan ruang berbudaya Betawi pada bangunan. 


\section{Hasil Design Ruang Berbudaya Betawi Kemayoran}

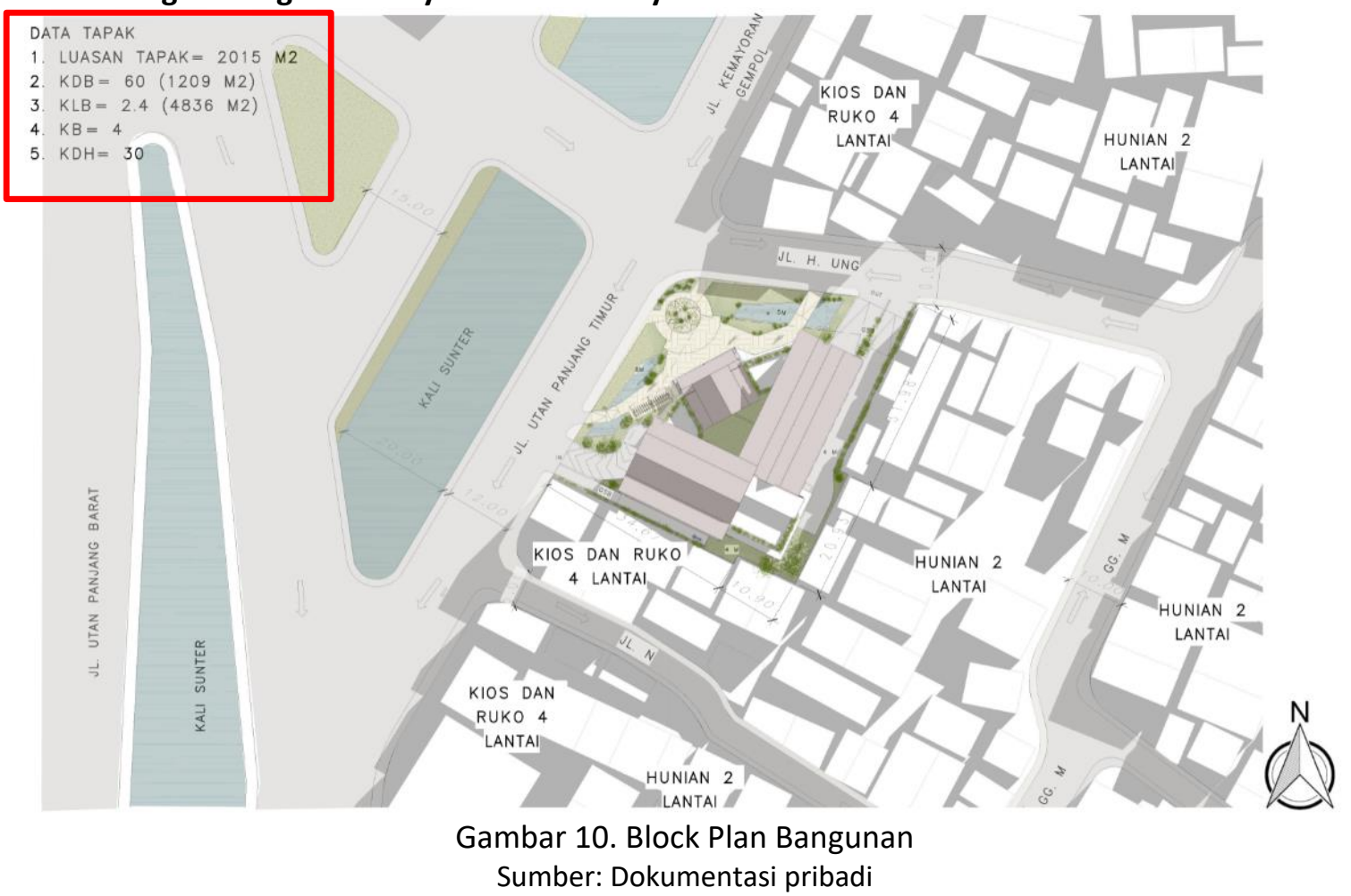

Rancangan Ruang Berbudaya Betawi Kemayoran ini mengambil bentukan dasar dari ondel-ondel dan bentukan dasar rumah adat Betawi yaitu persegi dan persegi panjang. Massa dibuat sama rata dengan jalanan dan terdapat massa yang melintang $90^{\circ}$ dari hoek perempatan jalan. Untuk parkir dan sirkulasi kendaraan di dalam tapak langsung dialirkan kebagian basement bangunan. Hal ini bertujuan untuk memberikan ruang terbuka untuk pejalan kaki. Maksimal daya tampung kendaraan 14 mobil pada area basement dan 15 motor.

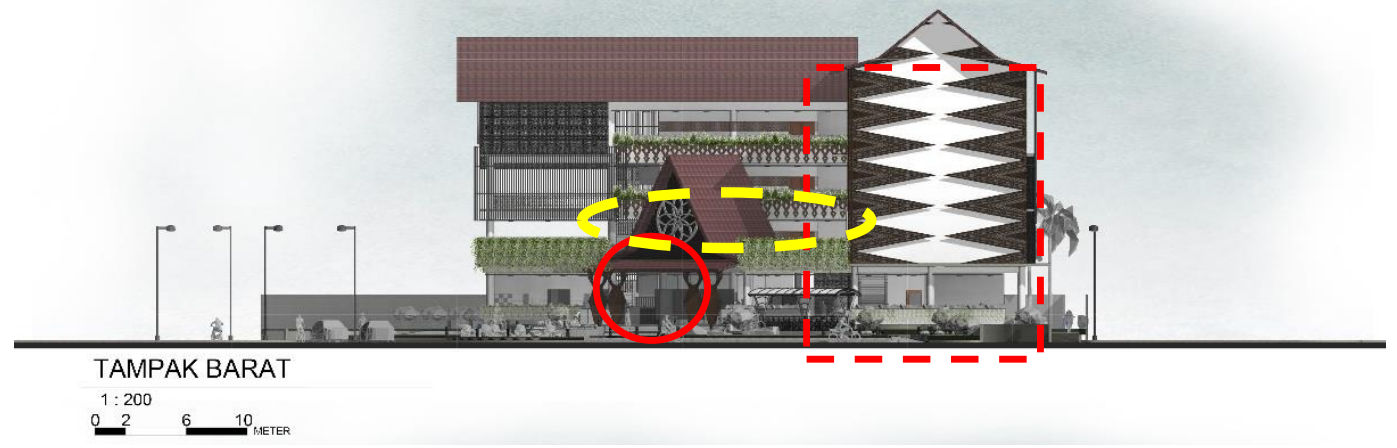

Gambar 11. Tampak Barat

Sumber: Dokumentasi pribadi

Pada gambar tampak barat bangunan dapat dilihat ornamen betawi yang banyak digunakan, seperti gigi balang, corak batik betawi, bunga lily, serta atap pelana khas rumah kebaya betawi. 
Diberikan massa yang melintang untuk menyambut pengendara dari arah Benyamin Sueb atau dari arah magnet kebudayaan betawi yaitu tugu ondel-ondel.

Tampilan dalam bangunan dibuat lebih terbuka dan menyatu dengan alam, pada bagian bawah bangunan ruang dibuat setengah terbuka yang diadaptasi dari rumah adat betawi yang memiliki selasar pada bagian depan rumahnya. Area tengah yaitu ruang komunal ini dibuat tinggi untuk memberikan kesan kemegahan akan kebudayaan Betawi yang ada.

\section{KESIMPULAN DAN SARAN}

\section{Kesimpulan}

Apabila kebudayaan lokal tidak segera dibenahi, maka lama kelamaan akan tergerus dan akan tergantikan dengan kebudayaan asing. Metode everydayness dari kegiatan masyarakat Betawi setempat digunakan untuk mengatasi permasalahan ini maka dibutuhkan ruang komunitas kebudayaan Betawi yang menjadi pusat perkenalan, pembelajaran dan penyebaran kebudayaan Betawi dan teknologi. Selain itu dimasa depan kebudayaan yang ada harus bisa beradaptasi dengan segala macam perubahan teknologi yang ada. Oleh sebab itu, dirancanglah sebuah ruang berbudaya Betawi berbasis teknologi.

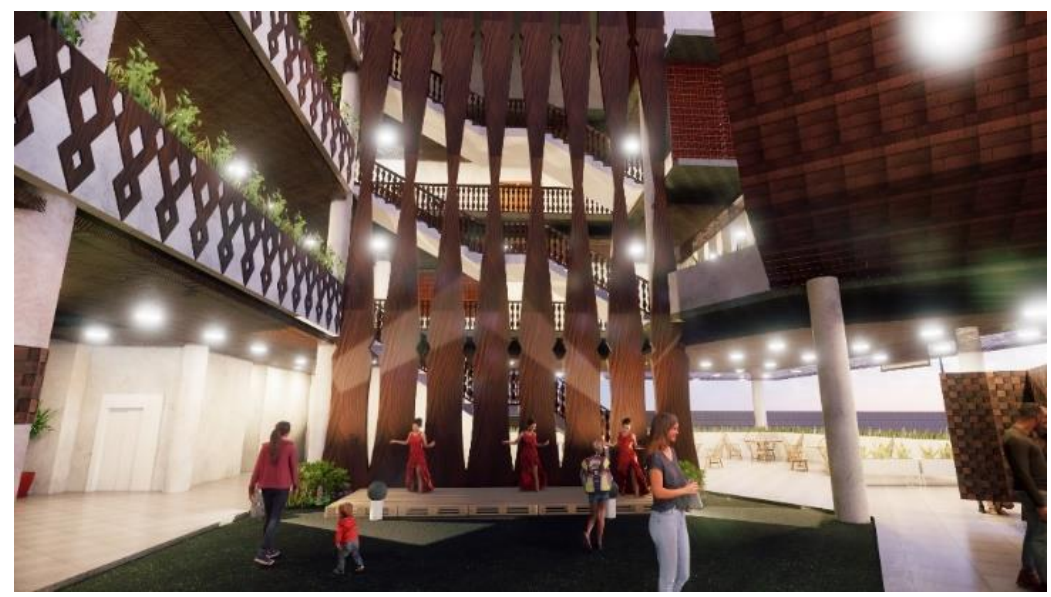

Gambar 12. Interior ruang komunal

Sumber: Dokumentasi pribadi

\section{Saran}

Hal yang perlu diperhatikan dalam merancang fasilitas ini adalah masalah dilupakannya kebudayaan lokal akibat kebudayaan asing dan cara masyarakat belajar untuk berkembang dengan kebudayaan baru, sehingga dapat melahirkan ruang kebudayaan baru dengan solusi dan program yang sesuai sebagai penyelesaian dari masalah yang terjadi. Upaya ini perlu didukung peran masyarakat serta dukungan dari pemerintah setempat.

\section{REFERENSI}

Broadbent, G. (1973). Design in Architecture. London: Wiley.

Crow, G., \& Allan, G. (1994). Community Life: An Introduction to Local Social Relations. Harlow: Pearson education.

Gandha, M. V. (2020). The Future of Dwelling, Kuliah Umum Tugas Akhir Studio Perancangan Arsitektur 8.30 Jurusan Arsitektur Universitas Tarumanagara Jakarta. Jumat 17 Juli 2020.

Hakim, A. F. (2019). UPK Perkampungan Budaya Betawi Setu Babakan Targetkan 400 Ribu Pengunjung Tahun Ini, (online) (https://jakarta.tribunnews.com/2019/06/22/upkperkampunganbudaya-betawi-setu-babakan-targetkan-400-ribu-pengunjung-tahun-ini, diakses tanggal (28 Oktober 2020). 
Heidegger, M. (1962). Being and Time. translated by John Macquarrie \& Edward Robinson. Oxford: Blackwell Publishers Ltd.

Jakartasatu. Gambar Peta Rencana Kota, diunduh tanggal 01 Januari 2021. https://jakartasatu.jakarta.go.id/portal/apps/webappviewer/index.html?id=1c1bfcced2cb 4852bbeaefcd968a6d04

Martin, J N., \& Nakayama, T. K. (2007). Intercultural Communication in Context (4thEd.). USA: Mc-Graw Hill International Edition.

Purbasari, M (2010). Indahnya Betawi. Jurnal HUMANIORA, Vol.1 No.1: 1-10. Edisi April.

Saidi, R. (1997). Profil Orang Betawi Asal Muasal, Kebudayaan, dan Adat Istiadat. Jakarta: PT. Gunara Kata.

Schulz, C. N. (1985). The Concept of Dwelling: On the way to figurative architecture. New York: Rizzoli International Publications, inc. dalam tesis Wolford. R (2008). Wandering in Dwelling. Washington State University.

Swadarma, D., Aryanto, Y. (2013). Rumah Etnik Betawi. Jakarta : Griya Kreasi.

Pengertian Kontemporer. http://kbbi.web.id/kontemporer (diakses tanggal 28 Oktober 2020). 
